\title{
Training in Endoscopy: Esophagogastroduodenoscopy
}

\author{
Joon Sung Kim and Byung-Wook Kim \\ Division of Gastroenterology, Department of Internal Medicine, College of Medicine, Incheon St. Mary's Hospital, The Catholic University of \\ Korea, Incheon, Korea
}

Gastrointestinal endoscopy is important in diagnosis, treatment, and prevention of many diseases of the digestive tract. The ability to perform esophagogastroduodenoscopy (EGD) safely, effectively, and efficiently has become the mainstay of gastroenterology practice. In Korea, EGD education is usually imparted as a component of gastroenterology training programs during fellowship. In this review, we discuss the general principles of EGD training. Formal curriculum development with devising clear goals and effective training methods should be developed in the future. Clin Endosc 2017;50:318-321

Key Words: Endoscopy; Education; Curriculum

\section{INTRODUCTION}

Gastrointestinal endoscopy is important in diagnosis, treatment, and prevention of many diseases of the digestive tract. In Korea, a nationwide screening program for gastric cancer was implemented in 2002 as part of the National Cancer Screening Program (NCSP). ${ }^{1}$ Biennial esophagogastroduodenoscopy (EGD) is recommended for adults aged 40 years or older to screen for gastric cancer. Endoscopic services are easily available in Korea as is evident from the rising numbers of EGDs performed annually. ${ }^{2}$ The diagnostic sensitivity of screening EGD for early gastric cancer in Korea appears to be lower than that in Japan. ${ }^{1}$ Due to increasing numbers of screening EGDs performed, maintaining high-quality performance is essential to enhance cancer detection at an earlier stage and to decrease the rate of adverse events. The ability to perform EGD safely, effectively, and efficiently has become the mainstay of gastroenterology practice.

Received: June 12, 2017 Revised: June 21, 2017

Accepted: June 21, 2017

Correspondence: Byung-Wook Kim

Division of Gastroenterology, Department of Internal Medicine, College of Medicine, Incheon St. Mary's Hospital, The Catholic University of Korea, 56 Dongsu-ro, Bupyeong-gu, Incheon 21431, Korea

Tel: +82-32-280-5052, Fax: +82-32-280-5987, E-mail: gastro@catholic.ac.kr

(cc) This is an Open Access article distributed under the terms of the Creative Commons Attribution Non-Commercial License (http://creativecommons.org/ licenses/by-nc/3.0) which permits unrestricted non-commercial use, distribution, and reproduction in any medium, provided the original work is properly cited.
In Korea, EGD training is usually imparted as a component of gastroenterology training programs lasting for at least 1 year during fellowship. The Korean Society of Gastrointestinal Endoscopy (KSGE) has developed the National Endoscopy Quality Improvement (QI) Program. ${ }^{3}$ Although the number of certified endoscopic specialists has been increasing, the vast majority of endoscopic procedures continue to be performed in primary clinics. Due to increased public awareness and growing legal pressure, the quality of EGD best practices has commanded greater attention. Variations in individual practice are likely to affect the efficacy of an EGD. Gastroenterology units should strive to ensure that trainees are competent enough to perform EGD safely and effectively at completion of training. Detailed technical skills required to perform an EGD have been reported previously. ${ }^{4}$ In this review, the general principles of EGD training will be discussed.

\section{CURRENT STATUS OF EGD TRAINING IN KOREA}

There is no standard methodology for EGD training. In Korea, trainees usually learn to perform EGDs under the supervision of an expert endoscopist. EGD training is achieved by a typical apprenticeship model. After observing a certain number of procedures performed by experts, trainees practice experiments on patients with specialists taking over at times 
Table 1. Recommendations Regarding the Minimum Number of Procedures Required for Competence

\begin{tabular}{lccc}
\hline Organization & EGD & Colonoscopy & ERCP \\
\hline American Society for Gastrointestinal Endoscopy $^{6}$ & 130 & 140 & 200 \\
British Society for Gastroenterology $^{7}$ & 300 & 100 & 150 \\
European Diploma of Gastroenterology $^{8}$ & 300 & 100 & 150 \\
Korean Society of Gastrointestinal Endoscopy $^{6}$ & 1,000 & 150 & 30 \\
\hline
\end{tabular}

EGD, esophagogastroduodenoscopy; ERCP, endoscopic retrograde cholangiopancreatography.

of difficulty. After completing a specified level of training, the trainee eventually acquires a certain degree of expertise. Recommendations regarding the minimum number of procedures required for achieving competence differ among various societies (Table 1). This method scores over others in terms of receiving direct supervision and feedback from an expert. ${ }^{5}$ However, the fact that only one expert endoscopist assumes responsibility for the teaching process and acquisition/refining of manual skills is a disadvantage. Additionally, as training programs do not need to be developed, patients are often exposed to discomfort with risk of adverse events until the trainee gains a sufficient level of efficiency. Moreover, training often fails to keep up with the requirements of modern EGD practices due to rapid technological advancements in EGD instruments. This has led to a critical review of the apprenticeship model. ${ }^{5}$ Therefore, in the interest of patient health and safety, it is essential to shorten the time required for trainees to gain competence through the development of effective training programs.

\section{GOALS OF TRAINING}

Competence in performing an EGD can be assumed once a specified number of procedures is completed. The minimum number is generally derived based on expert opinion or through consensus from major societies. It varies greatly depending on the society that makes the decision and ranges between 100 and $300 . .^{6-8}$ Currently, the KSGE specifies that a minimum of 1,000 EGD procedures be performed prior to certification; however, performing a predefined number of procedures does not ensure competence, which varies considerably among trainees. ${ }^{9}$ Recommended threshold numbers serve only as guidelines. Trainees should focus on acquiring and developing skills. Evaluation should include assessment of not only technical abilities but also cognitive skills. ${ }^{10}$ Trainees should be able to interpret endoscopic findings and incorporate them into overall patient care. Formal curriculum development with clear goals and effective training methods should be developed in the future.

\section{TEACHING AIDS}

EGD training might benefit from technological aids such as using simulators. Simulators being risk-free, patients are not exposed to unwarranted risks or discomfort. ${ }^{11}$ Trainees can focus on technical aspects of the procedure and help speed up the early learning curve. ${ }^{12}$ Simulators can also assess performance of trainees before they proceed to operating on patients. Requisite skills to perform EGD procedures have been traditionally categorized into technical, cognitive, methodological, and communicative abilities. ${ }^{13}$ Technical skills are related to handling the scope, viz., insertion and withdrawal, mucosal inspection and biopsy techniques. Cognitive skills relate to knowledge of endoscopic findings and application of these findings to clinical practice. Methodological skills involve understanding the sequence and methods used for routine EGD examination. Communication skills are needed to effectively communicate with assistants and to understand patient status. Unfortunately, no simulator can adequately satisfy all four functions performed by an EGD training program. ${ }^{14-16}$ Simulators focusing on sectional components of endoscopic maneuvers have been developed. ${ }^{17,18}$ Multiple studies have shown that virtual reality simulators can improve novice phase performance compared to non simulator training for the first 60-80 EGD procedures. ${ }^{19}$ Recently, a new simulator has been introduced to help beginners practice the endoscopic biopsy technique. ${ }^{13}$ Simulators have several advantagesthey can separate the EGD procedure into different individual steps such as insertion of the scope, biopsy, injection, clipping, and coagulation, and trainees can gain experience in performing each step of the procedure. After training in each phase, acquired skills can be collectively integrated. Unfortunately, simulator training alone does not appear to be sufficient for trainees to acquire skills necessary for EGD. A recent study comparing clinical training alone to simulator training revealed that adopting a combined training approach is the best method to learn diagnostic EGD. ${ }^{20}$ Studies describing simulator-based training for EGD are few compared to those reporting on colonoscopy or therapeutic endoscopy ${ }^{19,21,22} \mathrm{Ex}$ isting literature suggests that simulator training can reduce the overall procedure time and significantly improve technical 
accuracy. However, simulators are generally not used in Korea due to their costs and should be considered as part of EGD training in the future.

Live endoscopy courses, interactive teaching programs, and video materials can help trainees better identify pathological lesions. Because the prevalence of gastric cancer is high in Korea, diagnosis of gastric cancer is the most important objective of an EGD. Recently, it has been reported that an internet based e-learning system can improve the ability of endoscopists to diagnose gastric cancer at an early stage. ${ }^{23} \mathrm{In}$ ternet-based programs should be further developed to learn early identification and diagnosis of lesions.

\section{COMPETENCY ASSESSMENT OF TRAINEES}

Although quality indicators for EGD have been published, ${ }^{24-26}$ they cannot assess competency levels of trainees. Currently, there is no definite indicator for EGD, unlike adenoma detection rates or cecal intubation rates in colonoscopy. There is paucity of data in terms of assessment regarding what constitutes a complete procedure. Guidelines have defined technical success of EGD as retroflexion and visualization of the second part of the duodenum or recommended success rates of $\geq 95 \%{ }^{27}$ However, these guidelines are unlikely to accurately measure technical competency of a trainee. Likewise, there is no consensus on the minimum number of images to be taken during endoscopy. Recent European guidelines recommend a minimum of 10, while Japanese studies recommend a minimum of 22 in the stomach. ${ }^{23,26}$ Reportedly, an examination time of $\geq 7$ minutes can detect high-risk gastric lesions, with a three-fold greater probability of detecting dysplasia or cancer (odds ratio 3.42, 95\% confidence interval $1.25-10.38) .^{28}$ Based on such results, western guidelines have recommended an inspection time of at least 7 minutes for surveillance of intestinal metaplasia. Therefore, future studies should be performed to identify indicators that can measure EGD competency of trainees.

\section{ACQUIRING TEACHING SKILLS AS A TUTOR}

In Korea, EGD training is imparted by some endoscopists who have no education on how to teach endoscopy. Surgeons possessing a high level of expertise in performing an EGD are not necessarily effective trainers. ${ }^{29}$ Without effective training, most trainers fail to add much value to the teaching/training program. This contributes to passing on a legacy of inappropriate habits that might continue over an infinite number of cycles. Formal training courses should be developed for trainers to improve their educational approaches applied to endoscopy teaching. ${ }^{30}$ Such courses should focus on training/ teaching skills and not merely technical skills of the trainer.

\section{CONCLUSIONS}

Concepts of endoscopy training have evolved greatly and are continuing to undergo changes. The current apprentice model of training and competence assessment based on the number of procedures performed might not be sufficient any longer. Endoscopy training units should be supervised by a designated expert for training. Training should include the principles of sedation/analgesia techniques, obtaining informed consent, and knowledge of medical ethics. Structured training programs and curricula need to be developed to shorten the learning period. Teaching conferences should be further developed for education regarding correct interpretation of EGD findings and integrating them into medical or endoscopic therapy. Regular monitoring of the competence achieved by trainees after completion of training is essential.

\section{Conflicts of Interest}

The authors have no financial conflicts of interest.

\section{REFERENCES}

1. Cho YK. How to improve the quality of screening endoscopy in Korea: national endoscopy quality improvement program. Clin Endosc 2016;49:312-317.

2. Peery AF, Dellon ES, Lund J, et al. Burden of gastrointestinal disease in the United States: 2012 update. Gastroenterology 2012;143:1179-1187.e1e3.

3. Cha JM. [Quality improvement of gastrointestinal endoscopy in Korea: past, present, and future]. Korean J Gastroenterol 2014;64:320-332.

4. Lee SH, Park YK, Cho SM, Kang JK, Lee DJ. Technical skills and training of upper gastrointestinal endoscopy for new beginners. World J Gastroenterol 2015;21:759-785.

5. Dubé C, Rostom A. Acquiring and maintaining competency in gastrointestinal endoscopy. Best Pract Res Clin Gastroenterol 2016;30:339-347.

6. Eisen GM, Baron TH, Dominitz JA, et al. Methods of granting hospital privileges to perform gastrointestinal endoscopy. Gastrointest Endosc 2002;55:780-783.

7. Farthing MJ, Walt RP, Allan RN, et al. A national training programme for gastroenterology and hepatology. Gut 1996;38:459-470.

8. Beattie AD, Greff M, Lamy V, Mallinson CN. The European diploma of gastroenterology: progress towards harmonization of standards. Eur J Gastroenterol Hepatol 1996;8:403-406.

9. Chung JI, Kim N, Um MS, et al. Learning curves for colonoscopy: a prospective evaluation of gastroenterology fellows at a single center. Gut Liver 2010;4:31-35.

10. Walsh CM. In-training gastrointestinal endoscopy competency assessment tools: types of tools, validation and impact. Best Pract Res Clin Gastroenterol 2016;30:357-374.

11. van der Wiel SE, Küttner Magalhães R, Rocha Gonçalves CR, Dinis-Ribeiro M, Bruno MJ, Koch AD. Simulator training in gastrointestinal 
endoscopy - from basic training to advanced endoscopic procedures. Best Pract Res Clin Gastroenterol 2016;30:375-387.

12. Ekkelenkamp VE, Koch AD, de Man RA, Kuipers EJ. Training and competence assessment in GI endoscopy: a systematic review. Gut 2016;65:607-615

13. Ahn JY, Lee JS, Lee GH, et al. The efficacy of a newly designed, easy-to-manufacture training simulator for endoscopic biopsy of the stomach. Gut Liver 2016;10:764-772.

14. Camus M, Marteau P, Pocard M, et al. Validation of a live animal model for training in endoscopic hemostasis of upper gastrointestinal bleeding ulcers. Endoscopy 2013;45:451-457.

15. Hochberger J, Matthes K, Maiss J, Koebnick C, Hahn EG, Cohen J. Training with the compact EASIE biologic endoscopy simulator significantly improves hemostatic technical skill of gastroenterology fellows: a randomized controlled comparison with clinical endoscopy training alone. Gastrointest Endosc 2005;61:204-215.

16. Nelson DB, Bosco JJ, Curtis WD, et al. Technology status evaluation report: endoscopy simulators: May 1999. Gastrointest Endosc 2000;51:790792.

17. Schneider AR, Schepp W. Do it yourself: building an ERCP training system within 30 minutes (with videos). Gastrointest Endosc 2014;79:828832.

18. Sedlack RE. The Mayo colonoscopy skills assessment tool: validation of a unique instrument to assess colonoscopy skills in trainees. Gastrointest Endosc 2010;72:1125-1133, 1133.e1-e3.

19. Ferlitsch A, Schoefl R, Puespoek A, et al. Effect of virtual endoscopy simulator training on performance of upper gastrointestinal endoscopy in patients: a randomized controlled trial. Endoscopy 2010;42:10491056.

20. Ende A, Zopf Y, Konturek P, et al. Strategies for training in diagnostic upper endoscopy: a prospective, randomized trial. Gastrointest Endosc 2012;75:254-260.
21. Moorthy K, Munz Y, Jiwanji M, Bann S, Chang A, Darzi A. Validity and reliability of a virtual reality upper gastrointestinal simulator and cross validation using structured assessment of individual performance with video playback. Surg Endosc 2004;18:328-333.

22. Di Giulio E, Fregonese D, Casetti T, et al. Training with a computer-based simulator achieves basic manual skills required for upper endoscopy: a randomized controlled trial. Gastrointest Endosc 2004;60:196-200.

23. Yao K, Uedo N, Muto M, Ishikawa H. Development of an e-learning system for teaching endoscopists how to diagnose early gastric cancer: basic principles for improving early detection. Gastric Cancer 2017;20(Suppl 1):28-38.

24. Park WG, Shaheen NJ, Cohen J, et al. Quality indicators for EGD. Gastrointest Endosc 2015;81:17-30.

25. Cohen J, Safdi MA, Deal SE, et al. Quality indicators for esophagogastroduodenoscopy. Am J Gastroenterol 2006;101:886-891.

26. Bisschops R, Areia M, Coron E, et al. Performance measures for upper gastrointestinal endoscopy: a European Society of Gastrointestinal Endoscopy (ESGE) quality improvement initiative. Endoscopy 2016;48:843-864.

27. O'Mahony S, Naylor G, Axon A. Quality assurance in gastrointestinal endoscopy. Endoscopy 2000;32:483-488.

28. Teh JL, Tan JR, Lau LJ, et al. Longer examination time improves detection of gastric cancer during diagnostic upper gastrointestinal endoscopy. Clin Gastroenterol Hepatol 2015;13:480-487.e2.

29. Waschke KA, Anderson J, Macintosh D, Valori RM. Training the gastrointestinal endoscopy trainer. Best Pract Res Clin Gastroenterol 2016;30:409-419.

30. Walsh CM, Anderson JT, Fishman DS. Evidence-based approach to training pediatric gastrointestinal endoscopy trainers. J Pediatr Gastroenterol Nutr 2017;64:501-504. 